\author{
OAK RIDGE \\ NATIONAL LABORATORY \\ MANAGED BY UT-BATTELLE \\ FOR THE DEPARTMENT OF ENERGY
}

\title{
Efficiency of TTAC's ORTEC IDM
}

Jake Livesay, Jason Combs, Tim Margrave, Ian Miller August 2012

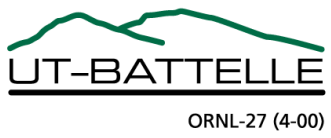


This report was prepared as an account of work sponsored by an agency of the United States Government. Neither the United States Government nor any agency thereof, nor any of their employees, makes any warranty, express or implied, or assumes any legal liability or responsibility for the accuracy, completeness, or usefulness of any information, apparatus, product, or process disclosed, or represents that its use would not infringe privately owned rights. Reference herein to any specific commercial product, process, or service by trade name, trademark, manufacturer, or otherwise, does not necessarily constitute or imply its endorsement, recommendation, or favoring by the United States Government or any agency thereof. The views and opinions of authors expressed herein do not necessarily state or reflect those of the United States Government or any agency thereof. 
Measurement Science and Systems Engineering Division Technical Testing and Analysis Center

Efficiency of TTAC's ORTEC IDM

Date Published: August 2012

\author{
Prepared by \\ OAK RIDGE NATIONAL LABORATORY \\ Oak Ridge, Tennessee 37831-6283 \\ managed by \\ UT-BATTELLE, LLC \\ for the \\ U.S. DEPARTMENT OF ENERGY \\ under contract DE-AC05-00OR22725
}


This page is intentionally left blank. 


\section{CONTENTS}

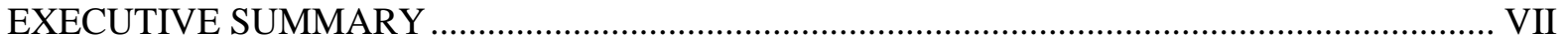

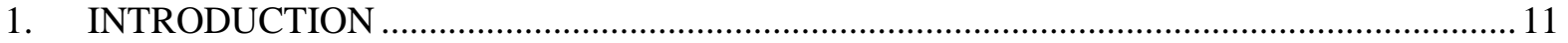

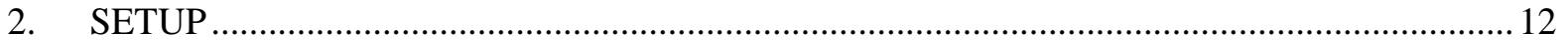

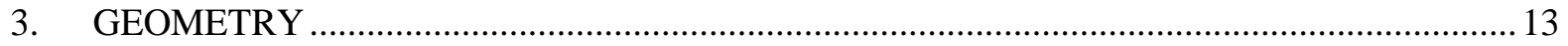

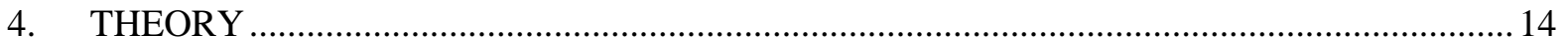

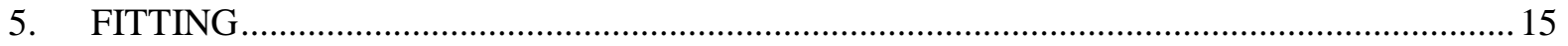

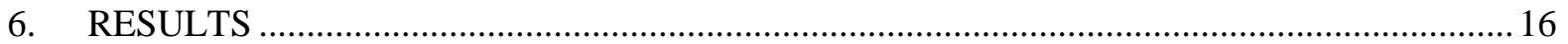

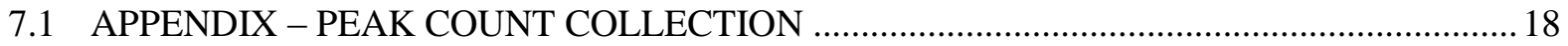

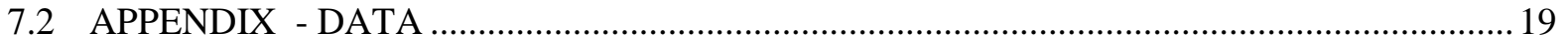

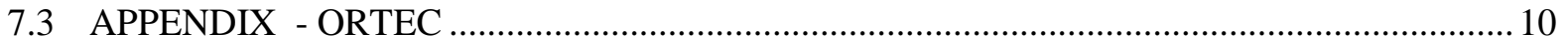

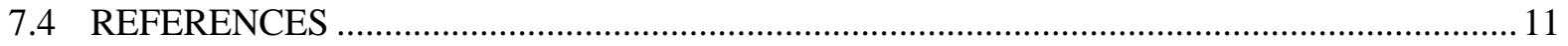


This page is intentionally left blank. 


\section{EXECUTIVE SUMMARY}

This report details the determination of the efficiency curve of an ORTEC High Purity Germanium Detector. The particular detector used in this work is owned by ORNL's Technical Testing and Analysis Center (TTAC), but the procedure is equally valid for any passive spectroscopic radiation detection system. 
This page is intentionally left blank. 


\section{INTRODUCTION}

ORNL's Technical Testing and Analysis Center (TTAC) acquired a High Purity Germanium Detector (HPGe) from ORTEC - a variant called an Interchangeable Detection Module (IDM). This detector has excellent energy resolution as well as high intrinsic efficiency.

The purpose of this report is to detail the determination of the efficiency curve of the IDM, so future measurements can quantify the (otherwise unknown) activity of sources. Without such a curve, the activity cannot be directly reported by use of the IDM alone - a separate device such as an ion chamber would be required. This builds upon the capability of TTAC.
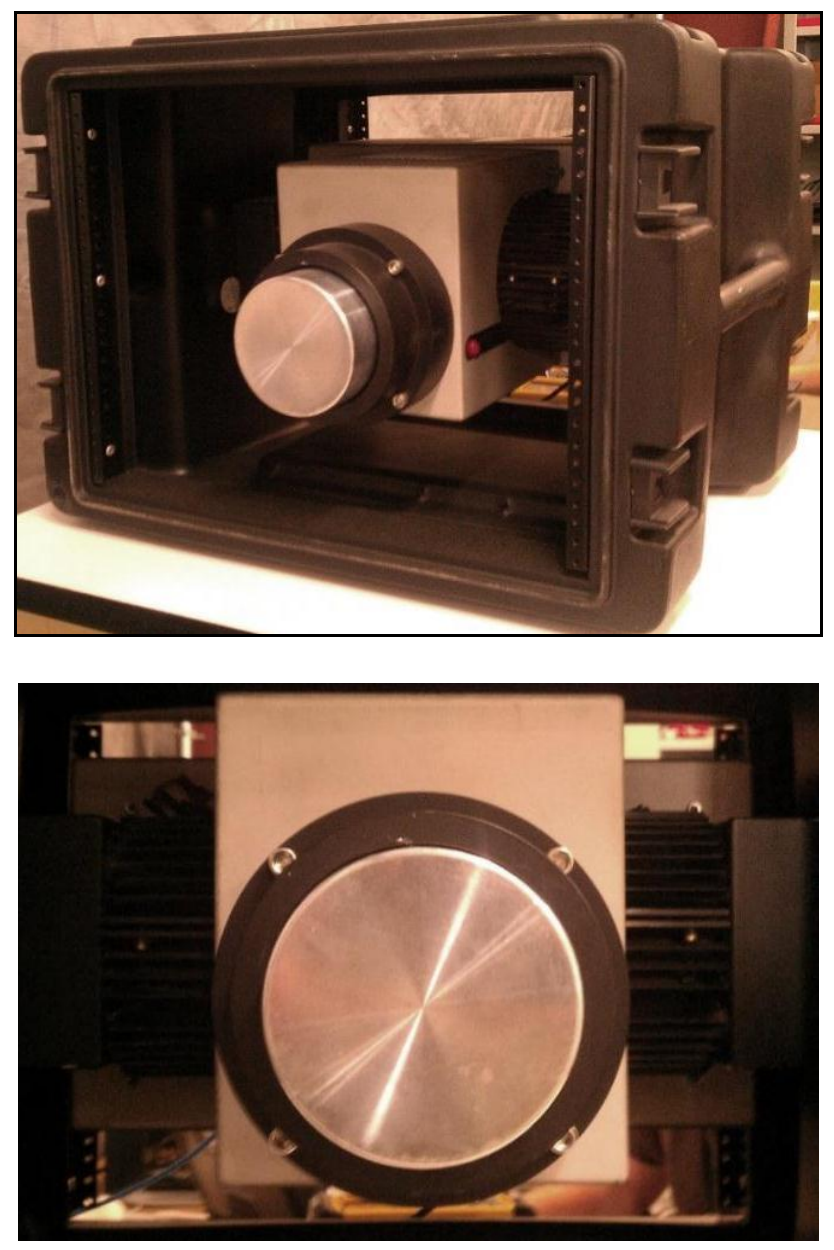

The method for determining the energy-dependent intrinsic efficiency is laid-out in the following sections. It's noteworthy that this basic technique can be applied to any spectroscopic radiation detector, independent of the specific type (e.g. Nal, CzT, ClYC). 


\section{SETUP}

The setup for the collection of data, for the eventual construction of the intrinsic efficiency curve, simply consists of a lab stand for holding sources at the height of the center of the detector. While, in principle, there is some scatter from the stand, floor, and air, these effects are not specifically characterized in this work. These effects can, however, be accounted for by use of shielding and/or collimation.

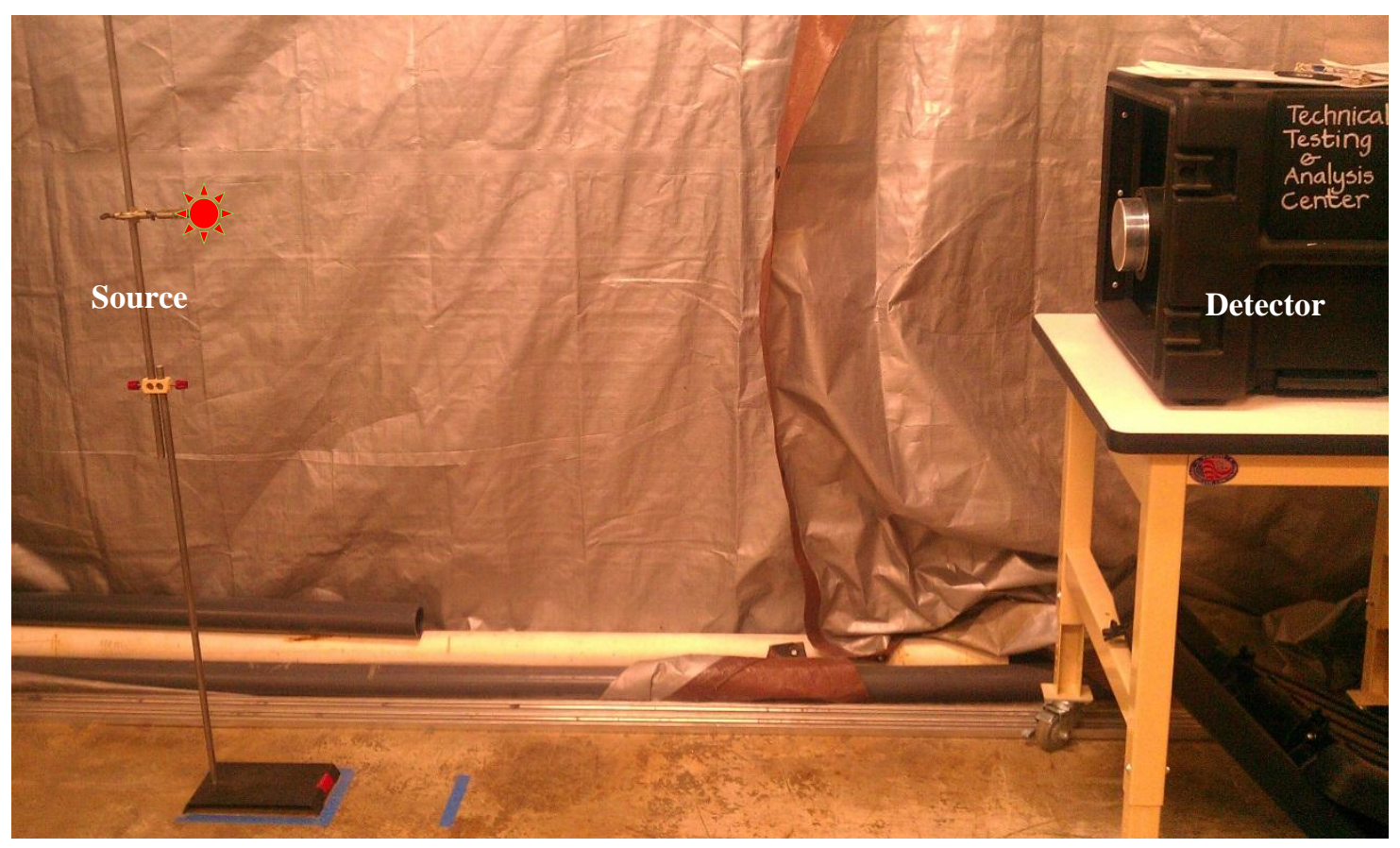

A variety of sources were held (one at a time) on the lab stand, and the spectra recorded by the IDM. Peak counts were recorded for the dominant gamma rays from each source and plugged into the intrinsic efficiency equation, seen below. The sources were chosen based on the wide-distribution of energies, which makes for a stronger fit to the data.

Spectra were collected by Maestro, ORTEC's MCA emulator software tool. 


\section{GEOMETRY}

The geometry of this measurement consists of only a few quantities, a positive consequence of symmetry. The center of the calibration sources were placed at the height of the center of the detector at a distance $(r)$ much greater than the dimensions of the sources and detector (d). In this work, the nearest sources were placed at $1.25 \mathrm{~m}$ from the detector, which is large compared to the detector diameter of $0.085 \mathrm{~m}$.

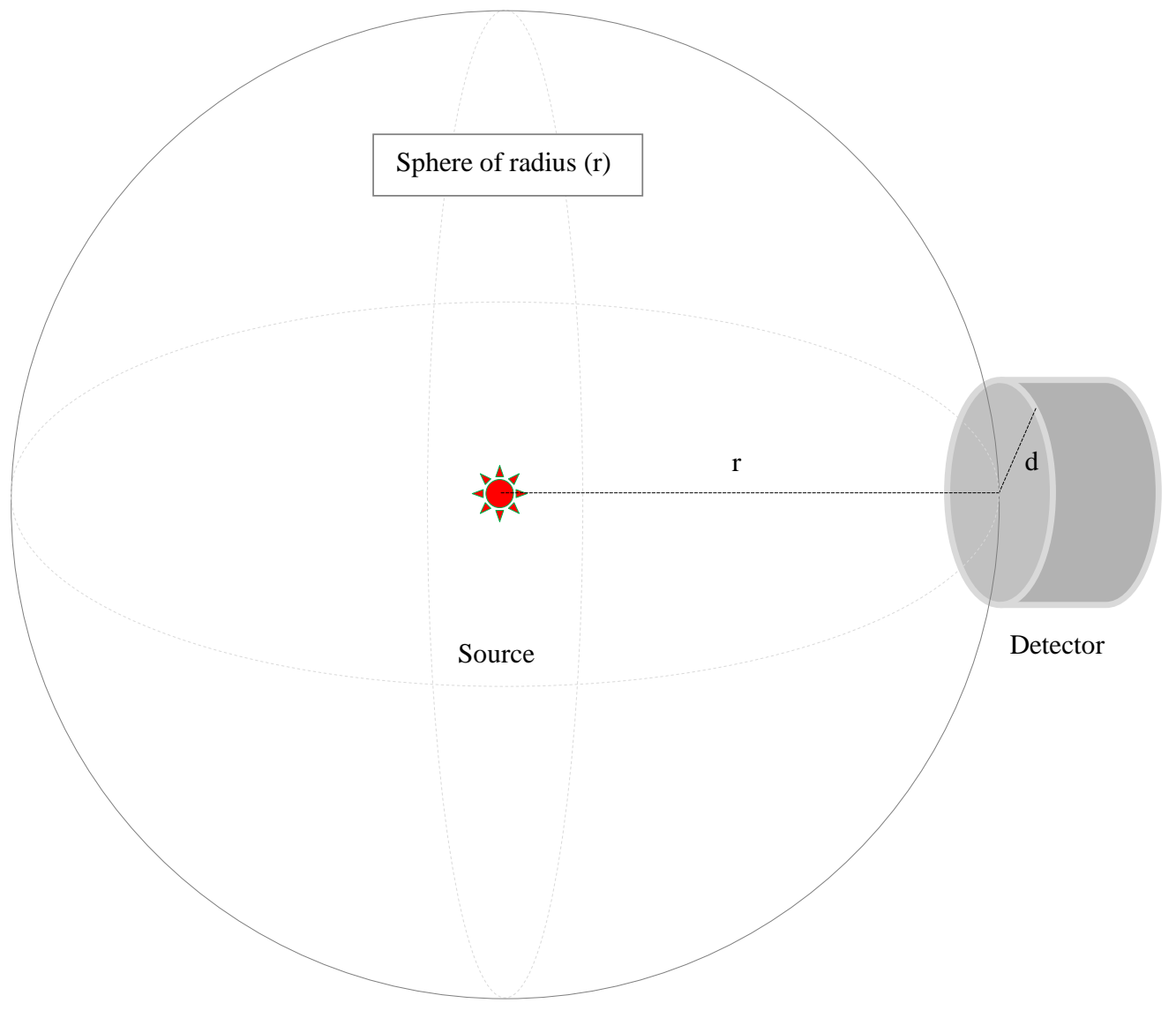

The distance between sources and the detector is chosen such that the "point source approximation" can be made. This means that the source appears like a point source from the perspective of the detector, and that the solid angle subtended by the detector, from the perspective of the source can be adequately approximated by the ratio of the surface area of the detector to the surface area of a sphere of radius ( $r$ ). Solid angle calculations are otherwise, generally, performed by Monte Carlo methods, which require programming and computing time. 


\section{THEORY}

The construction of an intrinsic efficiency curve is performed by illuminating a detector with radioactive sources of known strength. This efficiency curve is an intrinsic property of the detector - independent of distance and source strength - but its determination requires knowledge of all experimental variables. Once this information is gathered, it will not need to be done again and, measurements of the absolute activity of sources can be determined. The expression relating the measurable quantities follows:

$$
N=\varepsilon_{\text {int }} S t I \Omega
$$

Where $\mathrm{N}$ is the number of gamma rays detected, $\epsilon_{\text {int }}$ is the intrinsic efficiency of the detector (the probability of detection for each energy), $\mathrm{S}$ is the activity of the radioactive source (in units of "per second"), I is the intensity of the particular gamma ray being studied, and $\Omega$ is the solid angle subtended by the detector from the perspective of a point source located at the center of a sphere of radius $(r)$. The solid angle can be thought of as the fraction of all possible gamma ray trajectories impinging on the detector face. Rearranging the equation for $\epsilon_{\text {int }}$ and inserting an expression for the total activity of the source for the duration of the measurement yields the following:

$$
\varepsilon_{\text {int }}=\frac{N}{(S * t) I \Omega}
$$

The solid angle can be a tricky quantity to calculate (often requiring Monte Carlo techniques), but can be easily approximated when the distance $(r)$ between the source and detector is large compared with the detector area (and the source is small compared with the detector area). In this case, the solid angle can be written as the detector area (A) divided by the surface area of a sphere of radius ( $r$ ). Inserting this into the intrinsic efficiency equations:

$$
\varepsilon_{\text {int }}=\frac{N}{S t I \frac{A}{4 \pi r^{2}}}
$$

Inserting the detector area $\mathrm{A}$, where $\mathrm{d}$ is the detector radius, and performing a little algebra yields the final form of the intrinsic efficiency equation:

$$
\varepsilon_{\text {int }}=\frac{4 N r^{2}}{S t I d^{2}}
$$

This is the equation used to generate the column called Intrinsic Efficiency in the tables, below - See Appendix - Data. Intensities in this equation were taken from a website that aggregates such data [2]. 


\section{FITTING}

A function that fits all the physics that goes into the intrinsic efficiency curve is not easy to find. The equation shown below was copied from literature [1]. The parameters in Table 2 are a result of an Excelbased optimization routine called "Solver" (note: this is an Add In, basically goal seek for multiple parameters). Tabulated results can be found in Appendix-Data.

$$
\varepsilon_{\text {int }}(E)=\frac{P_{1}+P_{2} \ln (E)+P_{3} \ln ^{2}(E)+P_{4} \ln ^{3}(E)+P_{5} \ln ^{5}(E)+P_{6} \ln ^{7}(E)}{E}
$$

\begin{tabular}{|c|c|c|c|c|c|c|}
\hline$\chi^{2}$ & P1 & P2 & P3 & P4 & P5 & P6 \\
\hline 3.4 & 196491.2 & -150601 & 37449.14 & -2995.51 & -0.93621 & 0.094807 \\
\hline 3.5 & 199940.7 & -153933 & 38481.05 & -3100.45 & -0.94445 & 0.101757 \\
\hline 3.8 & 199771.3 & -153830 & 38456.65 & -3098.07 & -0.94463 & 0.101465 \\
\hline 8.7 & $3.06 \mathrm{E}-05$ & $5.46 \mathrm{E}-05$ & -3323.61 & 1153.705 & -20.0942 & 0.142556 \\
\hline
\end{tabular}

Table 1: Some of the parameter sets used to approximate the intrinsic efficiency data. There are slight differences in the fit, making each more slightly more suitable to different sections of the distribution.

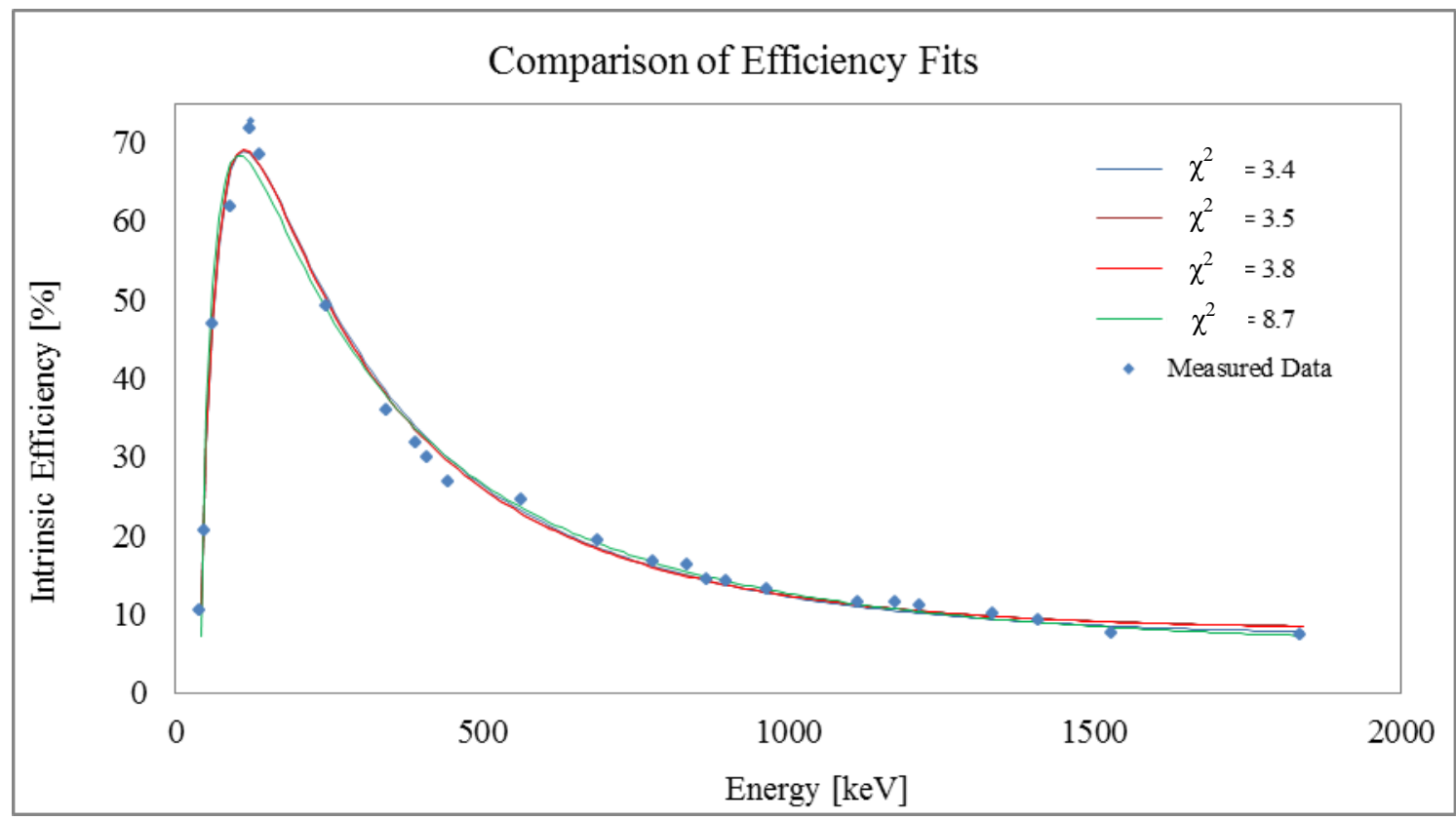

Figure 1: From a numerical perspective, Excel's Solver is very useful for multi-parameter searches. Keep in mind that the starting values of the parameters affects the final values, since the minimization routine must search through many local minima. Since fits tend not to be perfect (neither is the data for that matter), one must eventually choose the best. 


\section{RESULTS}

The intrinsic efficiency curve exhibits the expected characteristics, rising quickly to peak efficiency at around $120 \mathrm{keV}$ and tailing off at higher energies. A fit is especially useful for predicting the intrinsic efficiency of the detector for gamma ray energies, which lie between those already measured.

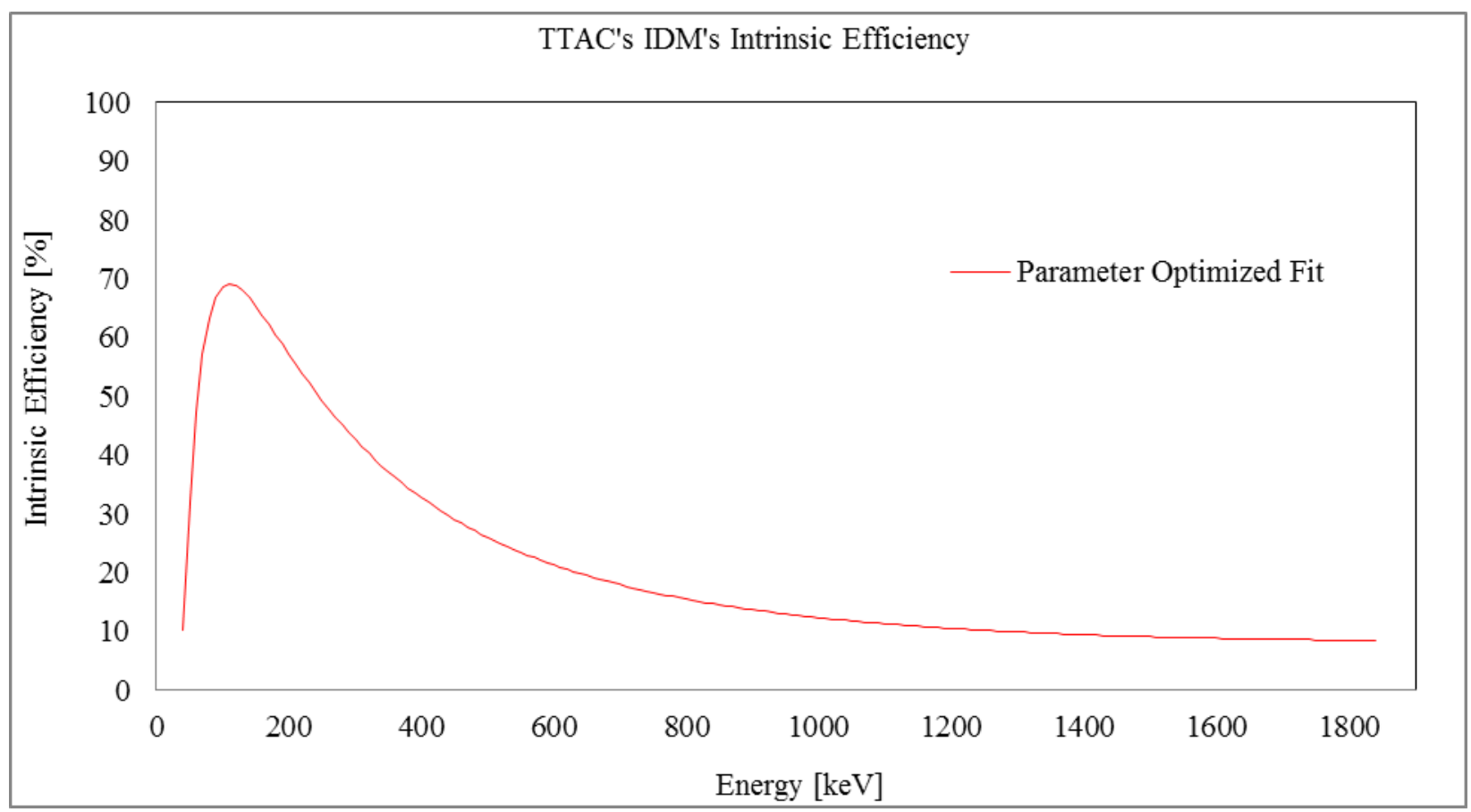

Figure 2: This plot presents the measured data alongside the best parameter set found with Excel's Solver function. For more on this subject see "Section - Fitting Function". This set of parameters was chosen for its low $\chi^{2}-$ and the classic eyeball-test.

Henceforth, this curve can be used to determine the activity of samples, by solving the intrinsic efficiency equation for source activity, thusly:

$$
S=\frac{4 N r^{2}}{\varepsilon_{\text {int }}(E) t I d^{2}}
$$

The intrinsic efficiency is written as an explicit function of energy as a visible reminder to consult the efficiency curve for each peak - see Section - Fitting Function for the parameter optimized fit. By the way, measurement of multiple gammas from a single source should yield the same source activity.

The resolution is another parameter of interest, which can be directly calculated from the peak width and centroid - tabulated in Appendix Data. It's noteworthy that the absolute resolution increases (degrades), while the relative resolution decreases (improves), with incident gamma ray energy. 


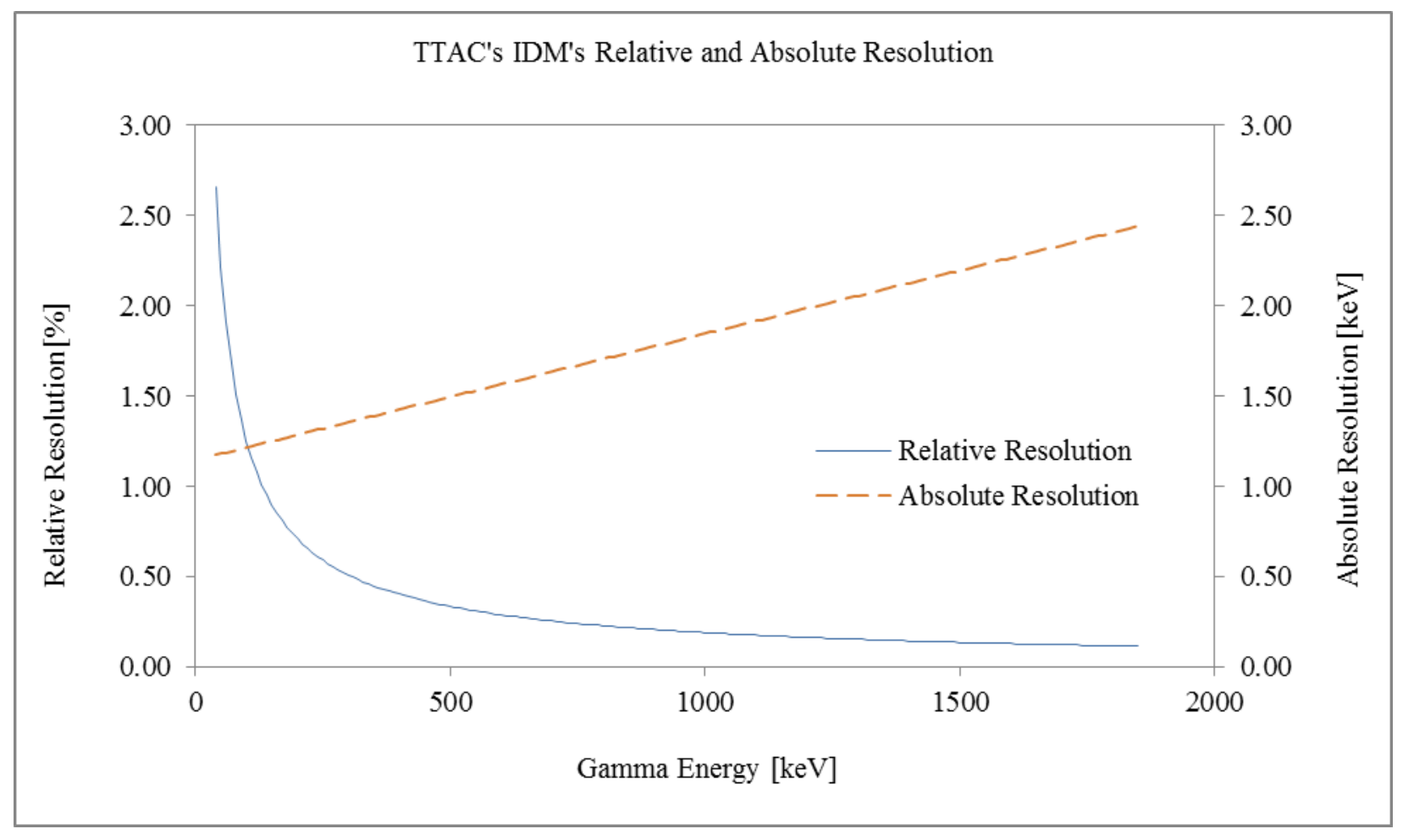

The functional (fitted) forms of these two resolution curves are much simpler than the one for efficiency (one is linear and the other is a power law). The fits were performed with all available data, in Excel.

$$
\begin{gathered}
R_{r e l}=54.492 E^{-0.819} \\
R_{a b s}=0.0007 E+1.1461
\end{gathered}
$$

$R_{\text {rel }}$ and $R_{a b s}$ respectively represent the Relative Resolution and the Absolute Resolution. 


\subsection{APPENDIX - PEAK COUNT COLLECTION}

The Peak Counts for the sources used in the determination of the intrinsic efficiency were collected by fitting a Gaussian distribution to the peaks and numerically integrating the fits. To save time, Peakeasy was employed after several fits were performed "by hand" in Excel and the results found to be well within $1 \%$ agreement.

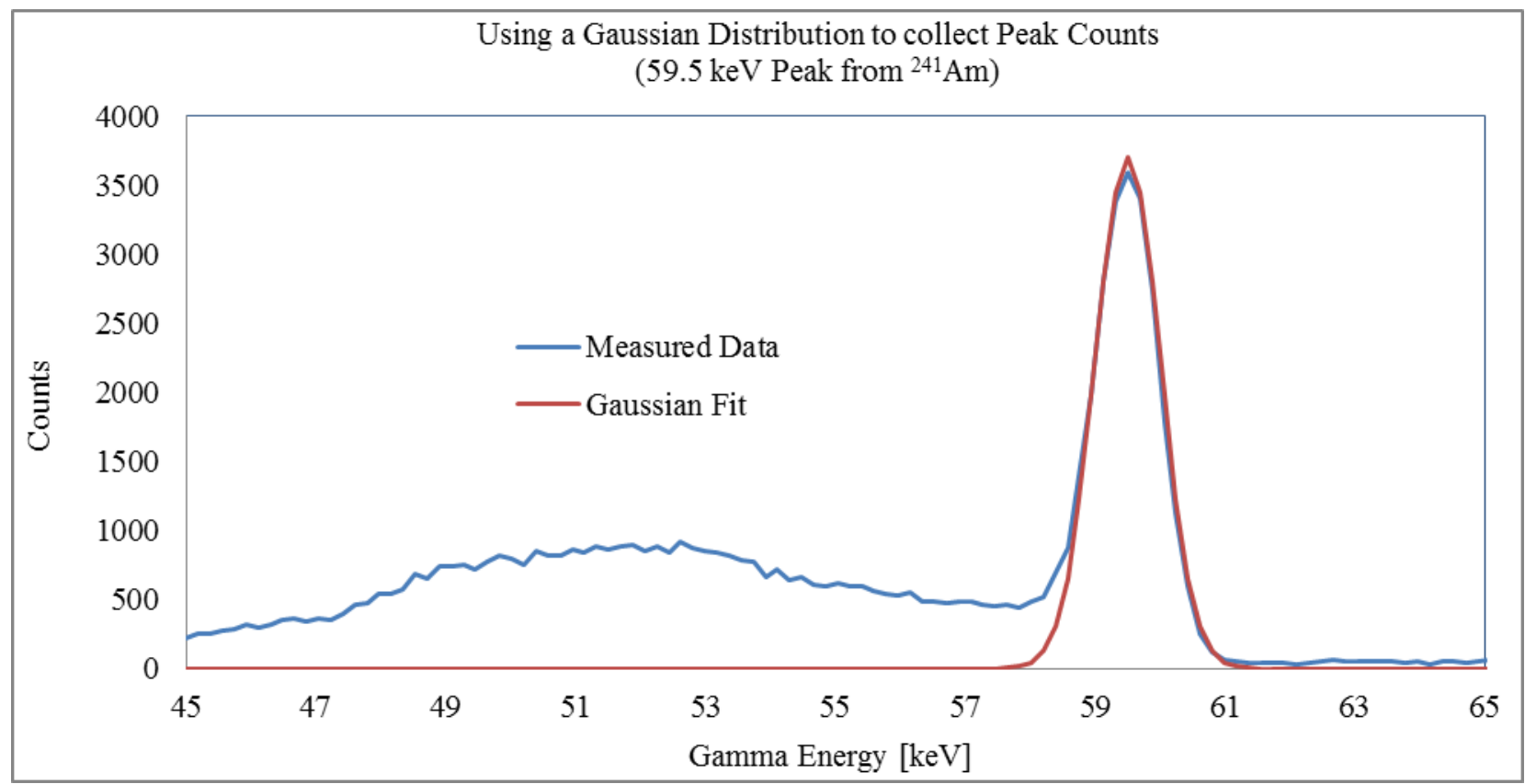

This is a straightforward method for collecting the peak counts and is an improvement on the ROI method because it directly yields the FWHM $\left(2.35^{*} \sigma\right)$ of the peaks. It's noteworthy that the "background" to the left and right of the peak are unequal - this is due to the fact that the left-hand background is a result of Compton scattering from the Photo peak, while the nearly-zero right-hand background is a reflection of the isolation of this peak relative to its higher-energy neighbors. So, this peak is not 'sitting on background', as is the case of other poorer-resolution detectors such as Sodium lodide (Nal) and Poly Vinyl Toluene (PVT). 


\subsection{APPENDIX - DATA}

\begin{tabular}{|c|c|c|c|c|c|c|c|}
\hline $\begin{array}{l}\text { Source } \\
(@ 1.5[\mathrm{~m}])\end{array}$ & $\begin{array}{l}\text { Peak Energy } \\
\text { [keV] }\end{array}$ & $\begin{array}{l}\text { Peak Counts } \\
\text { (900 seconds) }\end{array}$ & $\begin{array}{l}\text { Peak Width } \\
\text { [keV] }\end{array}$ & Intensity & Activity [Bq] & $\begin{array}{l}\text { Intrinsic } \\
\text { Efficiency }\end{array}$ & $\begin{array}{l}\text { Resolution } \\
\text { [\%] }\end{array}$ \\
\hline Am-241 & 59.5 & 45528 & 1.1 & 0.359 & 1498315 & 32.59 & 1.85 \\
\hline Cd-109 & 88 & 4982 & 1.2 & 0.037 & 1040144 & 49.83 & 1.31 \\
\hline Co-57 & 122 & 98950 & 1.2 & 0.856 & 819772 & 54.29 & 0.96 \\
\hline Co-57 & 136 & 12635 & 1.1 & 0.107 & 819772 & 55.56 & 0.84 \\
\hline Sn-113 & 392 & 13751 & 1.4 & 0.650 & 368372 & 22.12 & 0.36 \\
\hline $\mathrm{Mn}-54$ & 834.8 & 26820 & 1.7 & 1.000 & 916897 & 11.26 & 0.21 \\
\hline $\mathrm{Y}-88$ & 898 & 7762 & 1.8 & 0.937 & 322233 & 9.90 & 0.20 \\
\hline Co-60 & 1173 & 31174 & 2.0 & 0.999 & 1496465 & 8.03 & 0.17 \\
\hline Co-60 & 1333 & 26992 & 2.1 & 1.000 & 1496465 & 6.95 & 0.16 \\
\hline $\mathrm{Y}-88$ & 1836 & 4208 & 2.5 & 0.992 & 322233 & 5.07 & 0.13 \\
\hline $\begin{array}{c}\text { Source } \\
\text { (@ } 1.25[\mathrm{~m}])\end{array}$ & & $\begin{array}{l}\text { Peak Counts } \\
\text { (3600 seconds) }\end{array}$ & & & & & \\
\hline Eu-252 & 39.5 & $38875^{*}$ & 1.3 & 0.211 & 607281 & 10.52 & 3.28 \\
\hline Eu-252 & 40.1 & & & 0.383 & 607281 & & \\
\hline Eu-252 & 45.3 & $17156^{*}$ & 1.4 & 0.0374 & 607281 & 20.62 & 3.18 \\
\hline Eu-252 & 45.4 & & & 0.0724 & 607281 & & \\
\hline Eu-252 & 46.6 & & & 0.0239 & 607281 & & \\
\hline Eu-252 & 121.8 & 129535 & 1.2 & 0.2858 & 607281 & 73.28 & 0.95 \\
\hline Eu-252 & 244.7 & 23189 & 1.3 & 0.0758 & 607281 & 49.36 & 0.52 \\
\hline Eu-252 & 344.3 & 59156 & 1.4 & 0.265 & 607281 & 35.75 & 0.4 \\
\hline Eu-252 & 411.1 & 4154 & 1.4 & 0.0223 & 607281 & 29.88 & 0.34 \\
\hline Eu-252 & 444 & 5249 & 1.5 & 0.0282 & 607281 & 27.04 & 0.33 \\
\hline Eu-252 & 564 & 745 & 1.9 & 0.0046 & 607281 & 20.36 & 0.34 \\
\hline Eu-252 & 688.7 & 1037 & 1.6 & 0.0086 & 607281 & 19.36 & 0.23 \\
\hline Eu-252 & 778.9 & 13451 & 1.7 & 0.1294 & 607281 & 16.70 & 0.22 \\
\hline Eu-252 & 867.4 & 3793 & 1.7 & 0.0424 & 607281 & 14.36 & 0.19 \\
\hline Eu-252 & 964.1 & 11970 & 1.8 & 0.1461 & 607281 & 13.17 & 0.19 \\
\hline Eu-252 & 1085.9 & $6651^{*}$ & 1.9 & 0.1193 & 607281 & 8.96 & 0.17 \\
\hline Eu-252 & 1089.7 & & & 0.0173 & 607281 & & \\
\hline Eu-252 & 1112.1 & 9757 & 1.9 & 0.1364 & 607281 & 11.49 & 0.17 \\
\hline Eu-252 & 1212.9 & 983 & 2.0 & 0.0142 & 607281 & 11.11 & 0.17 \\
\hline Eu-252 & 1408.0 & 12049 & 2.2 & 0.2100 & 607281 & 9.22 & 0.15 \\
\hline Eu-252 & 1528.1 & 134 & 2.5 & 0.0028 & 607281 & 7.66 & 0.17 \\
\hline
\end{tabular}

Table 2: Europium is a great calibration source due to its many widely-distributed gamma rays. The Peak Counts marked with an asterisk $\left({ }^{*}\right)$ indicate that the detector resolution is insufficient to separate adjacent peaks, so their counts are summed, as are their intensities to properly account for the data. There is little additional loss of energy resolution, since those peaks are already indistinct. 


\subsection{APPENDIX - ORTEC}

This information is taken from an ORTEC document. The value for the detector diameter is the only piece of data used in the calculation of the intrinsic efficiency.

\begin{tabular}{|l|c|}
\hline \multicolumn{2}{|c|}{ Basic Detector Dimensions } \\
\hline Detector Diameter & $85 \mathrm{~mm}(+0 /-1 \mathrm{~mm})$ \\
\hline Detector Length & $30 \mathrm{~mm}(+3 /-0 \mathrm{~mm})$ \\
\hline Detector End Radius & N.A. \\
\hline Hole Diameter & $9+/-1 \mathrm{~mm}$ \\
\hline Hole Depth & $15 \mathrm{~mm}$ \\
\hline Hole Bottom Radius & $4 \mathrm{~mm}$ \\
\hline
\end{tabular}

\begin{tabular}{|c|c|c|c|}
\hline \multicolumn{4}{|c|}{ Miscellaneous Detector Assembly Dimensions and Materials } \\
\hline Identifier & Dimension & Description & Materials(s) \\
\hline A & $45 \mathrm{~mm}$ & Mount cup, length & Aluminum \\
\hline B & $6 \mathrm{~mm}(+/-1 \mathrm{~mm})$ & Mount cup base & Aluminum \\
\hline C & $3.2 \mathrm{~mm}$ & End cap window & Aluminum \\
\hline E & $0.5 \mathrm{~mm}$ & Insulator / Shield & POM*/Aluminum \\
\hline Front Window & $1.0 \mathrm{~mm} / 0.5 \mathrm{~mm}$ & Side contact layer & Ge (w/Li ions) \\
\hline F (Sides) & $200 \mathrm{micron}$ & Hole contact layer & Ge (w/B ions) \\
\hline $\mathrm{G}$ & $700 \mathrm{micron}$ & Mount cup wall & Aluminum / Stainless St. \\
\hline $\mathrm{H}$ & $0.3 \mathrm{micron}$ & End cap wall & Aluminum \\
\hline I & $0.79 \mathrm{~mm} / 0.38 \mathrm{~mm}$ & $\begin{array}{l}\text { NOTE: All aluminum and stainless } \\
\text { components have a 630 micron Ni plate on inside and outside } \\
\text { surfaces }\end{array}$ \\
\hline
\end{tabular}

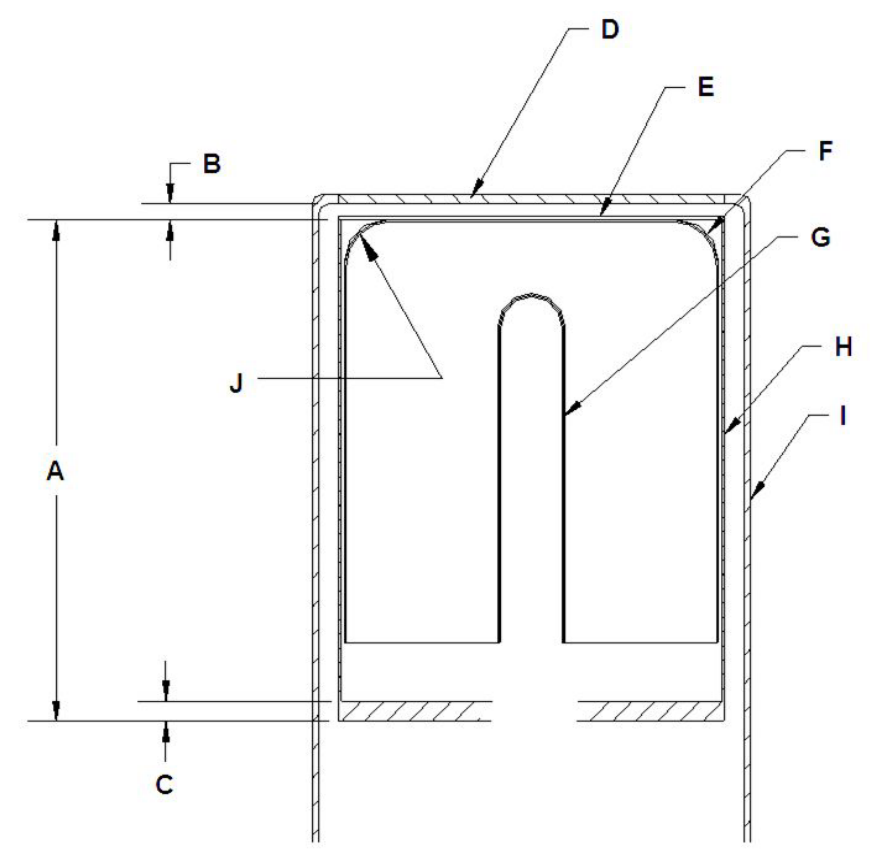




\subsection{REFERENCES}

[1] Study of Efficiency Calibrations of HPGe Detectors for Radioactivity Measurements of Environmental Samples, Harb, et al, Proceedings of the $3^{\text {rd }}$ Environmental Physics Conference, 19-23 Feb. 2008, Aswan, Egypt.

[2] http://www.nucleide.org/DDEP WG/DDEPdata.htm 